REVISTA CIENCIAS BIOMÉDICAS

LAS LETRAS DEL MAESTRO

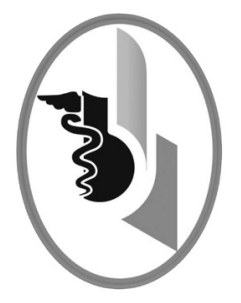

\title{
DIEZ COLUMNAS DE PRENSA DEL DOCTOR Y PROFESOR CARLOS BAUTISTA CRUZ ECHEVERRÍA*
}

\author{
TEN PRESS COLUMNS BY CARLOS BAUTISTA \\ CRUZ ECHEVERRÍA
}

Cruz-Echeverría Carlos ${ }^{1}$

\section{RESUMEN}

Se presentan fragmentos de diez columnas de opinión que fueron publicadas por el doctor Carlos Cruz Echeverría en las penúltimas décadas del siglo XX en periódicos de circulación regional en el Caribe colombiano. Se han hallado columnas de prensa desde 1982 hasta 1993. En muchas de sus columnas de opinión, el doctor Carlos Cruz Echeverría dejó su impronta de neurólogo y explicó a la comunidad el impacto y las consecuencias de diversas enfermedades desarrolladas en el tejido cerebral. Alertó tempranamente sobre la magnitud de la cisticercosis. Fue de los primeros en la Universidad de Cartagena que escribió sobre temas que hoy hacen parte de lo que se conoce como medicina del deporte. Certeramente expuso sus consideraciones sobre el desempeño del deportista y los riesgos del doping sin poseer el adecuado condicionamiento físico, nutricional y mental. Dedicó varias columnas al boxeo, del cual fue apasionado dirigente internacional y aficionado. Escribió sobre política, educación, sensibilidad social y atención primaria en salud, al abordar el tema de la obesidad. Su vida y obra está siendo estudiada por el Semillero de Investigación HISTORI-MED de la Facultad de Medicina de la Universidad de Cartagena. Las fotografías que ilustran este documento hacen parte de la Fototeca Histórica de la Medicina cartagenera. Rev.cienc. biomed. 2016;7(1):164-176.

\section{PALABRAS CLAVE}

Neurociencias; Ciencias de la nutrición y el deporte; Educación; Historia de la Medicina.

\section{SUMMARY}

There are fragments of ten columns of opinion that were published by Dr. Carlos Cruz Echeverría in the penultimate decades of the twentieth century in newspapers of regional circulation in the Colombian Caribbean. Press columns have been found from 1982 to 1993. Dr. Carlos Cruz Echeverría left his imprint of neurologist and explained to the community the impact and consequences of various diseases developed in the brain tissue in many of his opinion columns. He warned early about the magnitude of cysticercosis. He was one of the first at Universidad de Cartagena who wrote about topics that today are part of what is known as sports medicine. He certainly exposed his considerations about the athlete's performance and the risks of doping without adequate physical, nutritional and mental condition. He dedicated several columns to boxing, of which he was passionate international leader and amateur. He wrote

* Fragmentos. Reproducción de columnas de prensa publicadas originalmente en la década de los ochenta del siglo XX en periódicos colombianos. Trascripción realizada por Leidy Carolina Durán Méndez. Estudiante de Medicina. Integrante del Semillero de Investigación HISTORI-MED. Facultad de Medicina. Universidad de Cartagena. Colombia.

1 Médico. Neurólogo. Profesor de Neuroanatomía de la Facultad de Medicina de la Universidad de Cartagena. Colombia. 
about politics, education, social sensitivity and primary health care, addressing the issue of obesity. His life and work is being studied by the HISTORI-MED seminar of Medicine Department at Universidad de Cartagena. The photographs that pictures this document are part of the Historical Photo Library of Cartagena Medicine.Rev.cienc. biomed. 2016;7(1):164-176.

\section{KEYWORDS}

Neurosciences; Sports nutritional sciences; Education; History of medicine.

\section{NOTA DEL EDITOR}

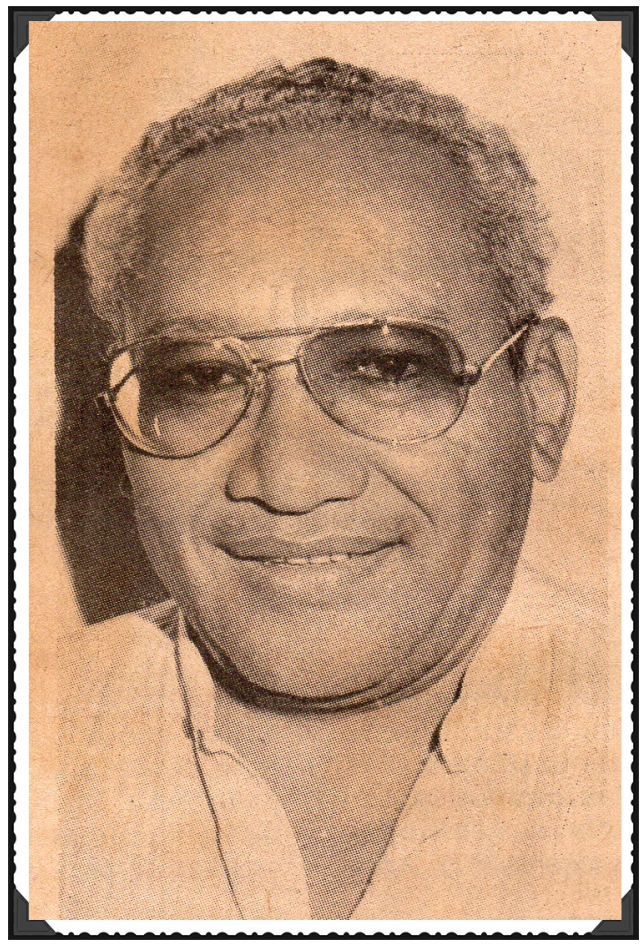

Dr. Carlos Bautista Cruz Echeverría

El doctor Carlos Bautista Cruz Echeverría fue un importante profesor de la Facultad de Medicina de la Universidad de Cartagena en las penúltimas décadas del siglo XX. Además de la importante labor docente que permite calificarlo como el más completo y connotado neuroanatomista de todos los tiempos de dicha escuela y uno de los gestores del inicio de las neurociencias, se destacó en las letras como columnista de prensa, labor en la que presentó su opinión crítica sobre la problemática social y política de sus tiempos.

Usó sus columnas de opinión como tablero para enseñar a los lectores y a la comunidad del Caribe colombiano, donde circulaban esos periódicos, sobre salud mental y enfermedades del sistema nervioso central.
Fomentó la prevención de enfermedades cerebrales usando un lenguaje sencillo, sin retórica, accesible a las personas del común, pero cargado a la vez de realidad científica y con la precisión que permitían los adelantos y los resultados de las investigaciones hasta ese momento cumplidas. Sus opiniones y documentos de prensa se ubican en un período de más de diez años, desde 1982 hasta 1993.

Su primera columna de prensa se denominó Convulsión, la cual inició un día del mes de octubre de 1982 en el periódico local de la ciudad de Cartagena llamado El Diario de la Costa. Luego explicó que le dio ese nombre porque las convulsiones se expresaban por una serie de sacudidas o contracciones musculares, debidas a descargas eléctricas recurrentes que se originaban en las neuronas que formaban la corteza cerebral por múltiples causas o enfermedades que podían llevar al organismo humano al deterioro o a la muerte; fenómenos que ocurren de forma similar en las sociedades humanas, produciendo sacudidas, ataques y convulsiones por diferentes causas: económicas, políticas, delictivas, etc., que traen como consecuencia la angustia y la reacción de los núcleos de población afectados. Esa visión de la realidad de su entorno quedó plasmada en todas y cada una de las publicaciones que realizó en dicha columna y que publicó por años. Cruz Echeverría combinó magistralmente lo inherente a las neurociencias y lo referente a la problemática social y política de la ciudad de Cartagena, de Colombia e incluso mundial, abordando temáticas de actualidad con honda repercusión comunitaria.

Carlos Cruz Echeverría fue pionero en la medicina del deporte; tuvo una columna en la sección de deportes de un periódico regional 
que denominó Deporte y medicina. Allí también combinó sus sólidos conocimientos del funcionamiento neuronal y la estructura cerebral con los aspectos referentes y propios del deporte. En muchos textos se nota su preocupación por las condiciones de salud de los deportistas en general, pero en particular por los boxeadores. El profesor fue dirigente deportivo nacional e internacional, miembro de comités técnicos y médicos de asociaciones mundiales de boxeo, en esos escenarios sentó cátedra y dejó escritos sobre los cuidados que ameritaban los boxeadores desde los inicios en cuanto a nutrición y salud mental. Propuso en encumbrados niveles de ese deporte la necesidad de estimar el coeficiente intelectual y la salud cerebral, cognitiva y mental de los deportistas y señaló con experticia médica y profesional lo siguiente: "El buen boxeador debe tener excelentes reflejos que le permitan los adecuados movimientos de desplazamiento, en defensa de su integridad física y le eviten los golpes a nivel de la cabeza que lesionen el cerebro".

Hoy día, cuando el boxeo ha tenido ascensos y descensos, cuando los dedos de las manos no alcanzan para contar los desenlaces lamentables o letales que se han presentado en ámbitos locales e internacionales, es justo recordar que el Dr. Carlos Cruz Echeverría escribió en 1984, hace más de 20 años, refiriéndose a los boxeadores y sus capacidades cognitivas: "Los boxeadores con un ligero retraso mental tienen dificultades para aprender una buena técnica y táctica, dificultades en la defensa y con esta falta de habilidad traen al boxeo una desacreditación y hacen al boxeo perder su función social dentro de las otras ramas del deporte".

También se destacó en las letras de ficción con dos relatos y una novela, donde conjugó su afán por educar, la tradición y la realidad de la Facultad de Medicina de la Universidad de Cartagena, dejando pistas y luces para el devenir de su historia. En esos textos está involucrada su otra pasión: la política como vocación de servicio para visibilizar las problemáticas sociales. Sus personajes están inspirados en la cotidianidad del boxeo, en sus amigos y en el entorno cartagenero y Caribe. Escritor de ficción con hondos matices costumbristas. Sus crónicas tienen el sabor de su propia vida.

El doctor Carlos Bautista Cruz escribió en Cartagena el 8 de diciembre de 1982, acerca de sus columnas de prensa: "Son el reflejo de mi conciencia de las realidades que se suscitan en mi medio ambiente, tal como las veo, las oigo, y las percibo en mi pensamiento y luego las materializo a través del lenguaje escrito en la prensa, son totalmente verídicas y espero sean un aporte a la conciencia social de la ciudad. Ojalá que ellas no ofendan a nadie y sean entendidas sanamente. Que ellas le sirvan de ejemplo estimulante a mis descendientes".

El doctor Cruz estudió en la Facultad de Medicina de Cartagena y perfeccionó sus estudios de Neurología Clínica en México. Viajó por numerosos lugares del mundo y ejerció siempre la medicina, la docencia, la escritura y la política en Cartagena. Fue miembro de la Academia de Medicina de Cartagena, a la cual ingresó el 7 de diciembre de 1989 presentando la ponencia Atrofia del cerebro durante el desarrollo histórico, en la cual sugirió que las comodidades de la civilización y condiciones de vida material en que viven los hombres han producido alteraciones estructurales en el cerebro.

Fue presidente activo del Club de Profesionales de Cartagena y Miembro del Consejo Superior de la Universidad de Cartagena. A continuación se presentan diez fragmentos seleccionados de sendas columnas de prensa que dejan ver su pensamiento y su enfoque conceptual de cómo educar a la comunidad y cómo mirar críticamente el entorno.

[1] Medicina y deporte. (Publicado en el periódico El Universal de Cartagena, sección de deportes el martes 23 de agosto de 1983). Un detalle que es digno de comentar en esta columna por su repetición, por el quebramiento de las normas contra la salud de los boxeadores, es el uso indiscriminado de las sales amoniacales. El amoniaco en solución es un gas bastante irritante de la mucosa de las fosas nasales, y carece de las propiedades estimulantes del sistema nervioso que tradicionalmente le han asignado. El uso de esta sustancia es empírico 


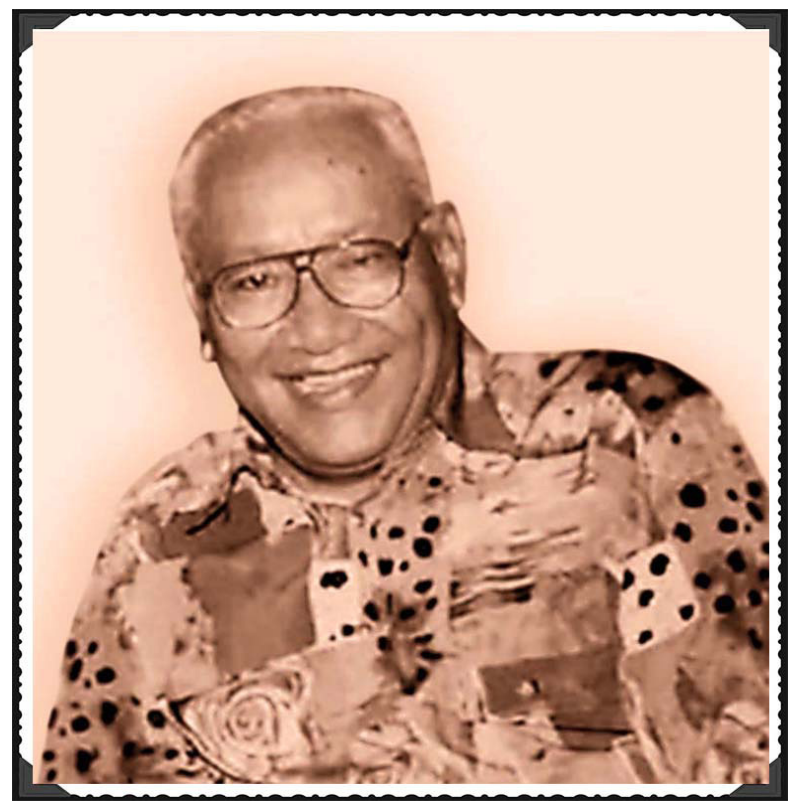

Dr. Carlos Bautista Cruz Echeverría

y anticientífico, en vez de proporcionar beneficios produce daños a la salud, su irritante olor es rechazado bruscamente por el organismo. Quizás esta costumbre inveterada tenga asidero en la creencia popular de que existen pociones maravillosas que aumentan la fuerza física del hombre. Muchos entrenadores hasta el día de hoy, siguen este tradicional patrón y le atribuyen propiedades singulares a los preparados vitamínicos, sales minerales y otras mezclas. Ciertamente estas substancias, en las mentes incultas, ejercen un efecto sicológico y de sugestión aumentando un tanto el pundonor de los boxeadores pusilánimes. Nunca los grandes registros y marcas en competencias deportivas se han alcanzado por este método. El sistema osteo-muscular responde en condiciones adecuadas al esfuerzo, cuando ha sido sometido previamente a un paciente y organizado entrenamiento. En los países en que el deporte se le aplica el rigor de la ciencia, el entrenamiento se completa con dieta balanceada, psicoterapia y hasta hipnosis. Ojalá los impacientes segundas destierren de sus mentes esta perniciosa costumbre del amoniaco que lo que ejerce es efecto nocivo para el boxeador.

[2] Los niños y la infelicidad. (Publicado en El Espectador/Costa el 27 de septiembre de 1984). Por todos lados la atención descubre crisis derivadas de las necesidades y carencias de dinero para resolver los asuntos oficiales y personales. El inconformismo y la ansiedad son los estados mentales más acuciantes. Entre todas las tragedias que percibimos a diario, la que más irrita y apesadumbra el pensamiento es la niñez desamparada e indefensa, -física y mentalmente-, a las contingencias de la naturaleza y a los efectos nocivos de las conductas e informaciones que deforman el comportamiento humano.

De tristeza y dolor de saber que en este país existen 2.5 millones de niños, que andan como ejércitos errabundos sin alimento, sin escuelas, ni seguridad social. La prensa refleja este drama, con las noticias de los gamines, los niños polizontes, que mueren congelados en barcos con rumbo a Alemania. El apego de la desesperación en sus calenturas mentes los lleva a sumir riesgos temerarios. Según las estadísticas del Instituto Nacional de Nutrición, realizados con investigaciones hechas entre 1977 y 1980 en niños menores de cinco años, se llegaron a la triste conclusión de que existe una tasa de $19 \%$ de desnutrición global, lo que equivale a que de cada cinco niños uno presenta problemas de crecimiento y retardo mental. Estas cifras aparentes, no incluyen los estados de hambre y desnutrición parciales de los restantes niños de estratos sociales bajos.

Es bueno recordar a los profanos, que el niño es el eslabón inicial de un proceso de formación de tejidos y aparatos, que concluye con la maduración de un fruto que es el hombre. Las etapas del proceso serán rápidas, normales o lentas e imperfectas de acuerdo al alimento y sus componentes las proteínas, las grasas, los hidratos de carbono, las vitaminas, el agua, etc. La desnutrición, - la enfermedad más extendida en el mundo libre- produce músculos y huesos debilitados y cortos, y el cerebro no realiza sus funciones intelectuales con la rapidez adecuada.

El niño es una criatura débil que necesita mucha protección familiar y oficial por las causas anotadas arriba, y debido a estas razones las Naciones Unidas han proclamado los Derechos del Niño, para protegerlos contra todos los atropellos hasta los políticos. 
En África del Sur hay miles de niños negros presos. En resumen, la felicidad es una de los derechos básicos del niño.

Desgraciadamente, en nuestra Patria, no se cumplen los tales derechos, ni las disposiciones de la ley colombiana y estamos formando una población de enanos con el cerebro liso (lisencéfalos), que se mueren temprano, son sensibles a las enfermedades, no producen y son una carga para la familia y el Estado. Estas cosas no se resuelven con teletones, ni olimpiadas.

El Gobierno debe garantizar los derechos establecidos en la Constitución y dar pan, cultura, recreación y deportes a los niños para que haya un verdadero desarrollo social, el cual no se conseguirá jamás por las vías del desarrollismo. La falta de alimento para los niños contrasta con la botadera de leche en las localizaciones de Valledupar y Ubaté, donde los trabajadores se han solidarizado y declarado en huelga, para que le paguen mejores salarios y prestaciones sociales. Pero los reyes del monopolio de la leche "Cicolac", no dan su brazo a torcer y prefieren botar la leche, antes que reconocer las justas demandas de los obreros. En otra oportunidad un rico avícola lanzó a un río miles de pollos con tal de no venderlos barato.

Aquí en Cartagena, quedarán por fuera del Instituto Colombiano de Bienestar Familiar cuatro mil niños, porque el Gobierno recortó la suma de 85 millones de pesos, por lo cual no permitirá una atención integral de los niños menores de siete años, los que tienen limitaciones físicas y mentales, los que tienen problemas de desnutrición. Por otro lado, es injustificable que las guarderías sean limitadas en sus beneficios y otras sean cerradas por falta de recursos económicos, lo cual acarrea un contratiempo laboral y emocional a las mujeres, que por necesidad de trabajar merecen que se les cuiden sus hijos. El niño es receptor de toda suerte de calamidades. Con células nerviosas atrofiadas, anémicos, reservorio de agresiones sexuales. En la vorágine de la calle modelan su mente en el quehacer de la delincuencia, para poder subsistir. La TV es el complemento para aumentar la inconformidad y estimar la agresividad.
Según nuestras leyes, catálogos de buenas intenciones, no debería haber ningún niño sin ocupación, pero paradójicamente y con el beneplácito de los organismos encargados de velar por el cuidado del niño, éste es utilizado como fuerza de trabajo y explotado inmisericordemente. La realidad es que en esta mezquina sociedad, el infante se ve forzado a trabajar para ayudar a la economía del tugurio, donde la madre abandonada padece de toda clase de inclemencias. No puede asistir al colegio porque el estado no tiene escuelas suficientes y no hay dinero para pagar la enseñanza privada.

[3] iCuídese de la solitaria! (Publicado en El Universal de Cartagena el 21 de diciembre de 1989). La nutrida consistencia que asistió a la reunión científica que se realizó en el Hotel Caribe, en relación con la neurocisticercosis salió asombrada con los datos que divulgaron los expertos sobre este terrible mal. Neurólogos y neurocirujanos y profesionales afines estudiaron, con amplitud y profundidad, los diferentes aspectos del problema. Este penoso mal existe desde los albores de la humanidad. Ocurre en forma crónica en los países tropicales y desaseados. No preocupaba tanto, porque se desconocía que los embriones y quistes de la Tenia Sollium vivían a sus anchas en el cerebro, sin que nadie los molestara. No había medios para descubrir los nocivos quistes. Las imágenes proporcionadas por la maravillosa escanografía cerebral, permitió ver a estos asesinos invasores en los pliegues y cavidades del encéfalo. Estas imágenes pueden compararse con un queso gruyere.

Estos hallazgos permitieron a los médicos hacer relación de la causa a efecto, con las diversas manifestaciones clínicas del mal: epilepsia, meningitis, demencia, cefalea, hidrocefalea, etc., y también con los hallazgos patológicos de autopsia. Se recordó en la reunión que las solitarias, en su raro ciclo biológico, habitan en el intestino del cerdo, y allí autoengendran -son hermafroditas- millones de huevos que son excretas que contaminan el suelo. La gente se infesta con los huevecillos ingiriendo aguas contaminadas, verduras, frutas, carne de cerdo, etc. Los huevos se transforman en larvas que luego atraviesan la pared 
intestinal y con habilidad, nadan por la sangre y colonizan el cerebro y músculos, en donde se enquistan por montones irritando el cerebro. Si los embriones enquistados no son molestados por un tratamiento adecuado, pueden vivir en esta situación 3 o 20 años, y luego se calcifican. El pleno reconoció con franqueza que no hay cifras propias que cuantifiquen la frecuencia de la neurocisticercosis. No obstante lo anterior, los especialistas a diario ven con asombro una enorme cantidad de imágenes de quistes en el cerebro. Esta impresionante evidencia fue la que los motivó para tocar campanas arrebato, y a denunciar los elevados índices de la enfermedad, sus nocivos efectos e implicaciones socio-económicas.

Hubo unanimidad de los asistentes en manifestar que es necesario y urgente declarar la guerra a este implacable enemigo -como si se tratara de un narcotraficante- con eficaces medidas sanitarias y medicamentosas, para erradicarlo y evitar riesgos y penas. Los ilustres profesionales denunciaron tenia -y su infinita familia- tiene garantizado su predominio catastrófico, mientras el estado no reaccione con adecuadas medidas.

La teniasis y sus metástasis cerebrales y musculares son reflejo de las vergonzosas condiciones antihigiénicas e incultura en la que vivimos. Para conocimiento de todos, la tenia no respeta clases sociales y la puede sufrir el encopetado y el marginado. El objetivo del evento fue el de entregar las conclusiones de la magnífica reunión a las autoridades de salud, para que tomen conciencia de la gravedad del mal. Inicien investigaciones y hagan despliegue publicitario que ilustre a la gente de todos los niveles para que desarrollen hábitos de higiene, control de cría y distribución de carne de cerdo, administración masiva de teniásicos a los infestados, etc.

[4] Puerto Rico y boxeo. (Texto publicado en la columna Convulsión de El Diario de la Costa de Cartagena en octubre de 1982. Entre el 4-8 de octubre de ese año se celebró en el Hotel Dupont Plaza de la ciudad de San Juan de Puerto Rico, la 61 Convención Anual de la Asociación Mundial de Boxeo Profesional [WBA] que congrega los máximos dirigentes, manejadores, empresarios y boxeadores del mundo). Asistí como delegado y Médico Neurólogo de la comisión de Boxeo Profesional de Colombia y tuve el gratísimo honor, de intervenir en las deliberaciones del Congreso y del Foro Médico que se realizó, en donde expusimos un trabajo científico titulado Los aspectos neurológicos del boxeo, que mereció, modestia aparte, una buena acogida.

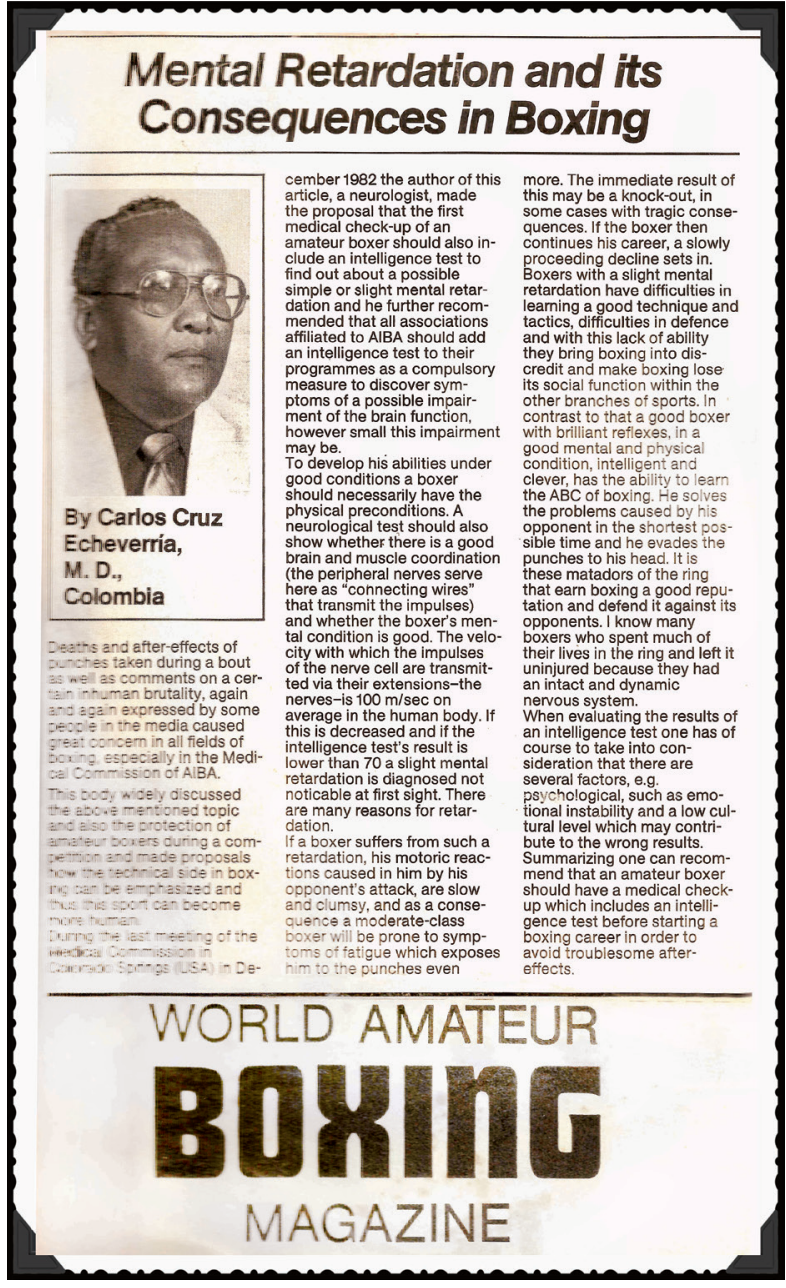

Facsímil de publicación en World Amateur Boxing Magazine. Número 10. Año 1984.

Entre los conceptos emitidos se destacan los siguientes: la función del sistema nervioso central en el hombre y en un boxeador en particular, es de vital importancia para producir las respuestas adecuadas que adopten el cuerpo humano a los estímulos del medio ambiente que se rodea, dentro del cual se haya ubicado, dentro de un ring, un boxeador enemigo en plan de agresividad, 
estimulado por alcanzar el triunfo, bien preparado física, mentalmente y con una buena técnica y estrategia.

Para que el organismo humano pueda ejercitar las funciones del boxeo, y el cerebro y los músculos, puedan producir la energía, que permita la conducción de los impulsos eléctricos y la contracción de los músculos, se necesita que exista un buen flujo sanguíneo. Por la masa encefálica debe circular $750 \mathrm{ml}$. de sangre en un minuto. Es indispensable el aporte de $5.5 \mathrm{ml}$. de oxígeno en un minuto por cada 100 gramos de tejido cerebral. Se requiere $6.6 \mathrm{mgs}$ de glucosa por cada $100 \mathrm{gms}$ de cerebro en un minuto. Los glóbulos rojos de la sangre, deben ser en promedio cuatro millones por $\mathrm{mm}$ cúbico, para transportar el oxígeno y el anhídrido carbónico. Solo en estas condiciones óptimas, se lleva a cabo un buen metabolismo cerebral y las respuestas adecuadas de defensa, ante la acometividad del contrato. Los impulsos nerviosos se conducen a una velocidad de $100 \mathrm{mts} /$ segundo, cuando existen las garantías anteriores; en caso contrario, las respuestas son retardadas. Como lo expresa el sentido común de los aficionados del Box., el buen boxeador debe tener excelentes reflejos que le permitan los adecuados movimientos de desplazamiento, en defensa de su integridad física y le eviten los golpes a nivel de la cabeza que lesionen el cerebro.

Los retardados mentales no deben estar dentro del boxeo. Se sugiere que a todo boxeador se le practique una medición de sus funciones mentales, mediante pruebas psicométricas.

[5] Los centros de estética y los gordos. (Publicado en el periódico El Espectador/ Costa el 9 de noviembre de 1985). El alimento es la base energética de la vida, hay quienes abusan y por tal razón engendran conflictos políticos, económicos, sociales y científicos. Malicio que para la mayoría del pueblo resulta chocante la campaña publicitaria a que viene sometido por medio de la Tv y en relación con los alimentos.

A cada rato y en forma inesperada aparecen en las pantallas unas guapísimas chicas, que con sus candorosos mensajes buscan orientar a la opinión. Dan datos acerca de los alimentos más abundantes, los de mejor precio, y cómo se deben confeccionar las variedades de platos. El complemento de este aderezo, mentiroso y ridículo, lo aporta el mitómano DANE, cuyos optimistas estudios y comunicados nos enteran acerca de la baja en el costo de los alimentos. Estas falaces campañas solo se cumplen en el mundo de la fantasía de sus creadores, porque el escaso número de habitantes que trabaja, gana sueldos de miseria que no les permiten gozar del mundo que pinta la TV. La abundancia cíclica de algunos alimentos, es el fenómeno natural de la época de cosechas.

Toda esta vocinglería socarrona es un espejismo de entretenimiento, que oculta el deterioro socio-económico. Aparentan que las cosas andan sobre rieles. La otra cara de la moneda, de esta sociedad de desnutridos y nutridos, son las personas que pueden comer capricho o voluntad, que la naturaleza castiga modelándoles un voluminoso cuerpo, que la imaginación popular denomina gordos. Estos queridos ilustres humanos, dentro del mundo constituyen un mercado que explotan los charlatanes de la salud, las industrias farmacológicas y los cirujanos.

Estas almas de Dios, viven en permanente agobio, por su antiestético aspecto físico, el temor al degeneramiento de sus arterias y la permanente mamadera de gallo de que los hacen víctimas sus contertulios. En la conciencia del obeso, se crea la idea, la necesidad, de perder grasa a como dé lugar. La preocupación se hace más ostensible entre las mujeres. Se desata una lucha entre el deseo y la tolerancia. En estas circunstancias vacilantes son presas fáciles de los sugestivos anuncios comerciales, que ofrecen curas milagrosas.

La obesidad es uno de los problemas más serios que enfrenta la medicina preventiva y la investigación. Los científicos y el sentido común se preguntan, el por qué hay diferencias de peso en animales de la misma edad, y colocados en las mismas condiciones ambientales y alimenticias. Corrientemente se utiliza el exceso de comida para cebar animales, que luego se exhiben ostentosamente en ferias. Los 
gordos son históricos, no han aparecido espontáneamente. En las obras de arte pictórico como las del maestro Durero se refleja el goce de los sentidos que existió en el siglo XVI por las rollizas. Hoy acontece lo contrario, y el maestro Botero zahiere a los hombres pintándolos con una adiposidad grotesca. Sus razones particulares tendrán.

Los gordos son personas bonachonas y se piensa que son personas desadaptadas ante las circunstancias desfavorables. Que su aparato mental no tiene suficiente aptitud para resistir los fracasos, las desgracias, la pérdida de un ser querido o cualquier frustración. El desequilibrio psíquico les engendra ansiedad, y para evadir esta situación ingieren alimento en forma obsesiva como un sustituto, se tranquilizan, pero el remedio los conduce a la obesidad. Estas personas necesitan el consejo científico de los endocrinólogos y dietistas, para que les hagan claridad en el pensamiento y autodisciplina para aceptar una dieta baja de calorías.

La mayoría de los bola de cebo son componentes de la clase que tiene elevados ingresos y poder para pagar una buena mesa de viandas y licores. Los carisecos son la antípoda del colesterol, son pobres y ligeros en el andar.

El mercado de los obesos y las personas que tienen tendencia a engordar ha hecho aparecer en las principales ciudades del país una miríada de centros de estética, cuya característica común es la de competir bajo el señuelo de quién tiene más habilidad para adelgazar a los adiposos sin ciencia. Hay algunos que ofrecen alegremente rebajar la bicoca de 14 kilos en cuatro días. Estas propagandas son falsas y anticientíficas. Alguien debería controlarlas. El colmo de la vaina es que hay algunos de estos centros que en su orgasmo llegan hasta hacer crecer a los enanos y a las mujeres que tienen mamas péndolas transformárselas, sin cirugía, en manzanas. Las píldoras mágicas y la cirugía mal aplicada contribuyen a distorsionar el tono mental de los panzudos.

La ciencia tiene ubicado el origen del mal en la llamada "grasa marrón", la cual es deficitaria en quienes tienen vocación de gordos. Algún día se conseguirá el remedio correcto y lo gordos se emanciparán de los charlatanes. Dejo constancia que no tengo ningún prejuicio contra los Sancho Panza, ni que estoy cargado a favor de Don Quijote. Por todos siento un gran respeto.

[6] El escritor y la realidad. (Publicado en el periódico El Universal de Cartagena el 19 de febrero de 1987). Hay quienes piensan ingenuamente que hacer estas cuartillas es cosa fácil y nada del otro mundo. En ocasiones algunas personas bien intencionadas y estimuladas por circunstancias momentáneas toman la decisión de dedicarse a estos menesteres. Desdichadamente, al rato, tiran la toalla en mitad del camino. Quienes tienen experiencia en estos asuntos conocen lo recio y la paciencia que demanda esta inclinación. Posiblemente quienes tienen la creencia de lo elemental que es escribir aún tienen arraigada en su conciencia el prejuicio de que la habilidad para escribir la determina un fenómeno ambiguo llamado "inspiración". Este concepto da la impresión de que en el cerebro de los escritores se produce un chispazo, o que un estímulo singular y eficaz es el que hace producir literatura. Hay otras personas que piensan que hay fuerzas sobrenaturales que iluminan el pensamiento. Estas interpretaciones son prosaicas y alejadas de la realidad. Crear una obra literaria, inventar algo o dictar una conferencia no es un simple juego de la imaginación. Es trabajo duro que exige ilustración, consumo de energía, tiempo y disciplina. Los descubrimientos de la ciencia, las grandes obras de la literatura y el arte son el fruto maravilloso de actividad del cerebro estimulado por el mundo exterior. Es palurda equivocación creer que hay ideas sin causa objetiva. Pienso que estos prejuicios son el recuerdo de las musas del Parnaso, que protegían e iluminaban el cacumen de los poetas helénicos.

La categoría de inspiración da la idea de que el proceso intelectual se produce sin trabajar, y la realidad es que los vagos jamás han producido nada. El concepto científico actual es que para crear algo de valor hay que poner en tensión todas las fuerzas psíquicas y se aumenta el metabolismo y procesos 
de excitación de la corteza cerebral hasta alcanzar la meta deseada. El buen estado del ánimo es el complemento que facilita el desarrollo de las capacidades psíquicas.

Por otro lado, es equivocada la opinión del libre albedrio 0 independencia de cerebro en la producción de pensamientos y actos voluntarios. El contenido de la conciencia y sus frutos los conceptos se recogen del ambiente social mediante la ayuda de los órganos de los sentidos. Para el cerebro del escritor, la materia prima para sus descripciones está en la realidad objetiva, insolublemente vinculada con su pensamiento. Esta realidad es múltiple y diversa, lo que acontece en el ambiente social, en el trabajo, la actividad y las interrelaciones profesionales, estudiantiles, los conflictos, las desigualdades e injusticias sociales, las folklóricas convenciones políticas, la oposición reflexiva la liquidación de la pobreza absoluta, la violencia, el fariseísmo, etc. Este es el carbón que suministra combustible a las neuronas para producir ideas, emociones y actos voluntarios. Es fuerza añadir que tendrá mayor claridad y profundidad quien tenga mayor cultura.

El famoso escritor Víctor Hugo en una ocasión sentenció: "Cuando escribo algo me olvido del mundo, pienso sobre esto cuando como, cuando duermo y cuando converso con alguien". En mis escritos no hago otra cosa que acomodarme de estas sabias normas y reencarnar en mi estilo las cosas y fenómenos que me circundan para tratar de ilustrar y luchar contra la explotación social, las lacras y el derrumbe de los valores humanos. Practico mi vocación y hago uso del derecho de pensar e informar.

\section{[7] El sentido común de la educación.} (Publicado el 8 de abril de 1985 en el periódico El Espectador/Costa). A cada rato los medios de comunicación recuerdan que estamos viviendo en el año de la educación. Martillan consignas que buscan dejar la impresión en las mentes ingenuas y desprevenidas de que se está haciendo un esfuerzo colosal para capacitar y desasnar al pueblo colombiano. Respeto y celebro estos entusiasmos paroxísticos, pero malicio que son catálogos de buenas intenciones que ni siquiera rebajarán los elevadísimos índices de analfabetismo y menos disminuirán la incultura de los alfabetos, por la sempiterna excusa de que no hay recursos económicos. A lo se suma la incompetencia y los intereses de los dómines que no les interesa, ni les conviene que se conozcan dónde radica el origen de las causas agobian al hombre colombiano y las leyes de la evolución, con lo cual se mantiene el estatismo.

\section{Carlos Cruz echevería La Reforma Universitaria}

En la actualidad se hace la reforma de los estatutos de las universidades colombianas y en particular la de Cartagena, en obedecimiento a lo estipulado por la Constitución del 91 y la Ley 30 , que reglamentó la elección de la administración universitaria. Este noble propósito persigue que sean los estamentos de la universidad -profesores, estudiantes y empleados- los que escojan las directivas en forma democrática, para que la administración se independice de las influencias dañinas de la política, responsables del auge burocrático, y se escojan los directivos más capaces dentro de la baraja de los postulados.

El doctor Carlos Cruz Echeverría abordó en su columna de opinión la problemática de la época referente a la educación universitaria.

La educación en el sentido amplio del concepto solo la usufructúan una minoría de la población. El autodidacta es una especie en extinción por lo inalcanzable de los libros y la falta de sustancia de los que se ofrecen. Desde los tiempos de Descartes estableció que los seres humanos gozan de la facultad de tener sentido común. La realidad es que son muy pocas las personas que gozan de esta propiedad de la materia viva, por la falta de oportunidades para cultivar el cerebro. 
Científicamente, el sentido común de Descartes es la síntesis de la actividad fisiológica de los cinco sentidos que se integran en la corteza cerebral y hace conciencia de los hechos y los objetos. El hombre recoge en su conciencia los estímulos y los problemas que suscitan relaciones humanas, con todo su contenido nocivo o agradable. El final de todo este proceso es una respuesta que se fija en los conceptos del lenguaje y comportamiento.

El hombre piensa como vive y el hambriento se agazapa en una esquina oscura para atrapar su víctima y poder satisfacer sus necesidades básicas. La persona que recibe educación científica-técnica y social tiene iluminada su conciencia, piensa con certeza, reconoce las mentiras disfrazadas de verdades y las causas de los problemas sociales y políticos que lo aguijonean, y busca los caminos adecuados para resolverlos. Los torpes son infinitos, no razonan, solo tienen conocimiento sensible de los estímulos corrientes, andan a ciegas, solo contemplan la superficie del mar, no la profundidad, actúan rutinariamente, enfrascados en conversaciones vulgares y asidos en forma terca a la tradición.

En condiciones de salud todos los hombres poseen el maravilloso instrumento de pensar, tienen los sentidos y la corteza cerebral, injustificadamente el alimento diversificado de la cultura no les es suministrado con igual intensidad y cantidad, por las razones, anotadas arriba y en muchos casos, por la holgazanería de las personas por aprehender las variedades científicas contenidas en los libros y la falta de popularización de estos preciosos objetos.

El arte del raciocinio lo practican con habilidad las personas que tienen conciencia de que poseen un cerebro y conocen las leyes que rigen el pensamiento, de allí la necesidad de enseñar a todos los niveles de la educación esta gimnasia que no es cosa del otro mundo. Los pueblos progresan cuando los hombres que están al frente de sus destinos tienen un pensamiento lógico y comprenden las necesidades y las exigencias sociales y dan las soluciones que se ajustan a la realidad. En nuestro medio el lugar común y el palabrerío hueco es el común denominador de los líderes.

Duele señalar que en materia de educación estamos a la zaga y la característica común es la ignorancia a todos los niveles, y, como consecuencia de ello estamos frenados en el desarrollo social y económico. La desmirriada educación que se administra con cuenta gotas cada día se debilita más y son vergonzantes las frecuentes huelgas a que tienen que apelar los maestros y las universidades para exigir el pago justo y oportuno de sus salarios. Los afanes de la educación deben ser continuos, no de un año y masivos para que el hombre colombiano pueda incorporarse a la producción material e intelectual y pueda ver con claridad lo que ocurre a su alrededor. El hombre se transforma en más hombres cuando se cultiva intensamente, se humaniza. El hombre que no se educa tiene una conciencia infantil y se aproxima a sus antecesores. Es loable la determinación de la ONU de declarar el año 85 como el de la educación con el objetivo de llamar la atención de los pueblos para erradicar la ignorancia.

Cabe señalar que la atención no solo se debe fijar en la lacra del analfabetismo, sino que se debe hacer un cambio profundo en la concepción total de la instrucción, la cual debe impartirse en forma integral, el conocimiento de los problemas naturales y sociales. No es posible que la educación siga produciendo tecnócratas que desconocen la realidad de nuestro país. Las ciencias sociales deben ser impartidas con las leyes del pensamiento humano, lo contrario es vivir en la Edad Media. La incultura y la desocupación son los motores que algún día harán saltar una chispa de consecuencias imprevisibles, de allí la urgencia de que los mecanismos del estado y las ideologías se actualicen y hagan uso de los instrumentos adecuados que den respuesta a la ebullición del ámbito social.

[8] Las transfusiones olímpicas. (Nota editorial en el periódico El Universal. Cartagena. Enero de 1985). Hoy nos sobresalta el hecho inaudito contenido en las declaraciones de Don Miller, presidente del Comité Olímpico de USA (COEU), 
quien cariacontecido y ante las evidencias, tuvo que confirmar a la prensa el suceso vergonzoso de deportistas que participaron con éxito en los Juegos Olímpicos de Los Ángeles, recibieron transfusiones de sangre no terapéuticas, sino con el objetivo de aumentar su fortaleza y resistencia en las competencias ciclísticas.

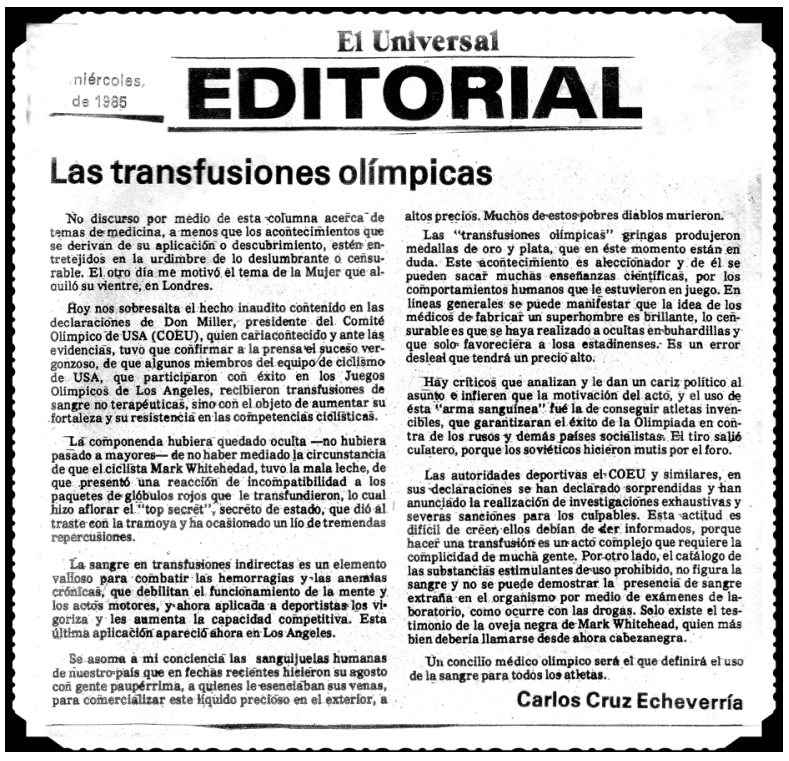

Facsímil de columna de opinión.

Periódico El Universal de Cartagena. Enero de 1985.

La componenda hubiera quedado oculta - no hubiera pasado a mayores- de no haber mediado la circunstancia de que el ciclista Mark Whitehedad, tuvo la mala leche, de que presentó una reacción de incompatibilidad a los paquetes de glóbulos rojos que le transfundieron, lo cual hizo aflorar el "top secret", secreto de estado, que dio al traste con la tramoya y ha ocasionado un lío de tremendas repercusiones.

La sangre en transfusiones indirectas es un elemento valioso para combatir las hemorragias y las anemias crónicas que debilitan el funcionamiento de la mente y los actos motores, y ahora aplicada a deportistas los vigoriza y les aumenta la capacidad competitiva. Esta última aplicación apareció ahora en Los Ángeles. Se asoman a mi conciencia las sanguijuelas humanas de nuestro país que en fechas recientes hicieron su agosto con gente paupérrima, a quienes le esenciaban sus venas para comercializar este líquido precioso en el exterior, a altos precios. Muchos de estos pobres diablos murieron.
Las "transfusiones olímpicas" gringas produjeron medallas de oro y plata, que en este momento están en duda. Este acontecimiento es aleccionador y de él se pueden sacar muchas enseñanzas científicas, por los comportamientos humanos que le estuvieron en juego. En líneas generales se puede manifestar que la idea de los médicos de fabricar un superhombre es brillante, lo censurable es que se haya realizado a ocultas en buhardillas y que solo favoreciera a los estadounidenses. Es un error desleal que tendrá un precio alto.

Hay críticos que analizan y le dan un cariz político al asunto e infieren que la motivación del acto, y el uso de esta "arma sanguínea" fue la de conseguir atletas invencibles, que garantizaran el éxito de la olimpiada en contra de los rusos y demás países socialistas. El tiro salió culatero, porque los soviéticos hicieron mutis por el foro.

Las autoridades deportivas el COEU y similares, en sus declaraciones se han declarado sorprendidas y han anunciado la realización de investigaciones exhaustivas y severas sanciones para los culpables. Esta actitud es difícil de creer, ellos debían de ser informados, porque hacer una transfusión es un acto complejo que requiere la complicidad de mucha gente. Por otro lado, el catálogo de las sustancias estimulantes de uso prohibido, no figura la sangre y no se puede demostrar la presencia de sangre extraña en el organismo por medio de exámenes de laboratorio, como ocurre con las drogas. Solo existe el testimonio de la oveja negra de Mark Whitehead, quien más bien debería llamarse desde ahora cabezanegra. Un concilio médico olímpico será el que definirá el uso la sangre para todos los atletas.

[9] Convulsión. (Columna de opinión publicada por vez primera en un día de octubre de 1982 en el Diario de la costa de Cartagena). Se me ha ocurrido titular esta columna con el nombre de Convulsión, quizás por la especialidad que ejerzo, la neurología, pero más que todo por la semejanza que existe entre el organismo humano y nuestro organismo social en relación con este fenómeno.

Las convulsiones como enfermedad se expresan clínicamente por una serie de sacu- 
didas o contracciones musculares, debidas a descargas eléctricas recurrentes que se originan en las células o neuronas que forman la corteza cerebral, -que es la copa superficial que recubre los hemisferios cerebrales-, como respuesta del sufrimiento del cerebro por múltiples causas que sería prolijo enumerar y que pueden llevar al organismo humano al deterioro o a la muerte si no se hace diagnóstico oportuno y acertado.

En las sociedades humanas ocurren fenómenos similares, se producen sacudidas, ataques permanentes, convulsionan por diferentes causas, económicas, políticas, delictivas, etc... que traen como consecuencia la angustia y la reacción de los núcleos de población afectados.

En la actualidad el desarrollo social y económico del país se encuentra deteriorado por el desigual reparo de la riqueza, concentrada en una minoría económica, que denomina y explota a la gran mayoría, además, el desequilibrio fiscal del Gobierno, que ha sido expresado por varios gobernadores al declarar la bancarrota de sus departamentos, lo cual impide el desarrollo de planes de vivienda, salud, educación y recreación cultural. La existencia de un elevado porcentaje de desempleo, originando en la falta de inversión y planificación de la producción, que permita los ingresos necesarios para adquirir los bienes materiales necesarios para un mejor desarrollo de la vida de la colectividad, sin sacudidas ni convulsiones.

Como consecuencia lógica de los anteriores hechos, se ha entronizado la descomposición social, la inversión de valores: el malo es el bueno. El código de ética y moral que rige la sociedad ha perdido vigencia.

[10] Retraso mental y sus consecuencias en el boxeo. (Publicado en World Amateur Boxing Magazine. Número 10. Año 1984. Se publicó en inglés, alemán, español, francés y ruso). Las muertes y las secuelas de los golpes tomados durante una pelea, así como los comentarios sobre cierta crueldad inhumana, repetidas veces expresadas por los medios de comunicación, causaron gran preocupación en todos los campos del boxeo, especialmente en la Comisión Médica de la AIBA.

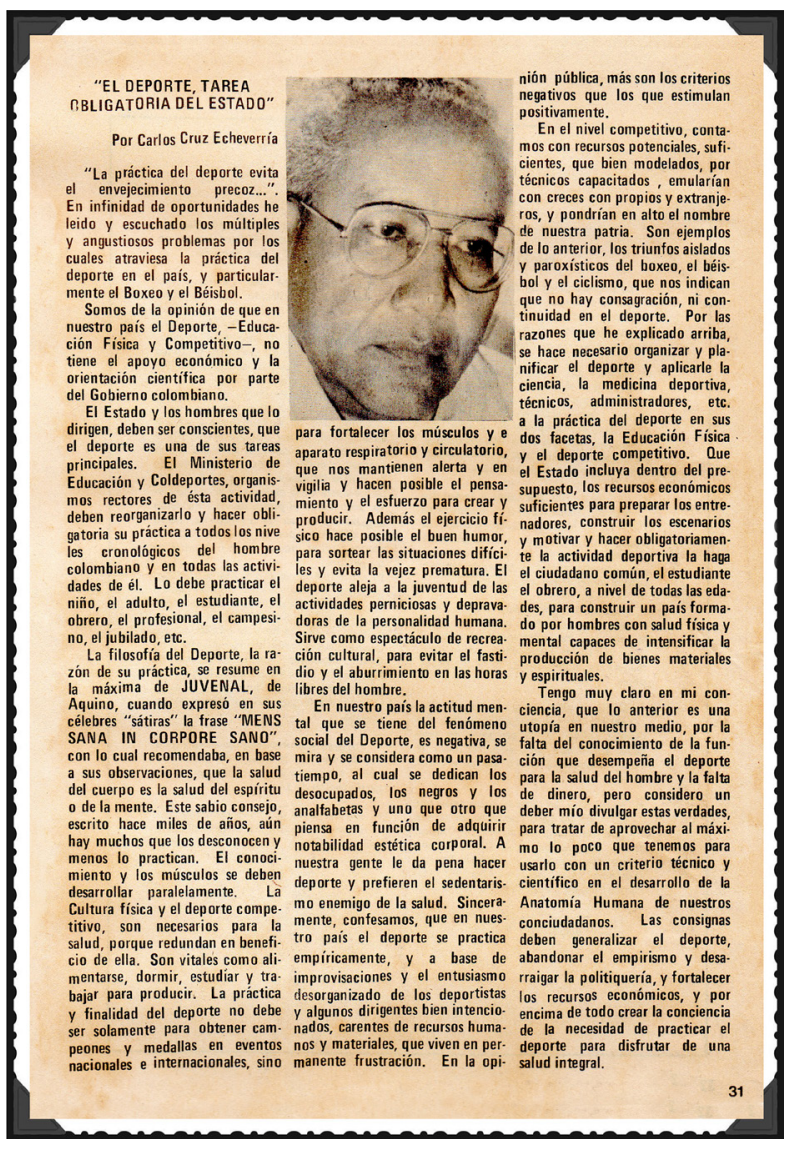

Este órgano discutió ampliamente el tema antes mencionado y también la protección de los boxeadores aficionados durante una competencia y formuló propuestas sobre cómo se puede enfatizar la técnica $y$, por lo tanto, este deporte puede volverse más humano.

Durante la última reunión de la Comisión Médica en Colorado Springs (USA) en diciembre de 1982 el autor de este artículo, neurólogo, hizo la propuesta de que el primer chequeo médico de un boxeador aficionado incluyera también una prueba de inteligencia para averiguar sobre una posible reanudación mental simple o leve y recomendó además que todas las asociaciones afiliadas a AIBA deben añadir una prueba de inteligencia a sus programas como una medida obligatoria para descubrir síntomas de un posible deterioro de la función cerebral por pequeño que sea este deterioro.

Para desarrollar sus habilidades en buenas condiciones, un boxeador debe necesariamente tener el físico. Una prueba neurológica también debe mostrar si hay una 
buena coordinación cerebral y muscular (los nervios periféricos sirven aquí como "cables de conexión que transmiten y si los impulsos están en buena condición"). La velocidad con la que los impulsos nerviosos son transmitidos a través de sus extensiones, los nervios son de $100 \mathrm{~m} / \mathrm{segundo}$ en promedio en el cuerpo humano. Si esto disminuye y si el resultado de la prueba de inteligencia es de 70 , un leve retardo mental se diagnostica sin ser notado a primera vista. Hay muchas razones para el retraso.

Si un boxeador sufre de retraso, sus reacciones motrices causadas en él por el ataque de su oponente son lentas y torpes, y como consecuencia un boxeador de clase moderada será propenso a síntomas de fatiga que lo exponga a los golpes incluso más. El resultado inmediato de esto puede ser un golpe de knock-out, en algunos casos con consecuencias trágicas. Si el boxeador continúa su carrera, comienza lentamente el descenso. Los boxeadores con un ligero retraso mental tienen dificultades para aprender una buena técnica y táctica, dificultades en la defensa y con esta falta de habilidad traen el boxeo una desacreditación y hacen al boxeo perder su función social dentro de las otras ramas del deporte.

En contraste con eso un buen boxeador con reflejos brillantes, en una buena condición mental y física e inteligente, tiene la capacidad de aprender el ABC del boxeo. Resuelve los problemas causados por su oponente en el menor tiempo posible y evade los golpes en su cabeza. Son estos matadores del anillo los que ganan boxeo de buena reputación y lo defienden contra sus oponentes, conozco a muchos que pasaron gran parte de su vida en el ring y lo dejaron ileso porque tenían un sistema nervioso intacto y dinámico.

Cuando se evalúan los resultados de una prueba de inteligencia, es evidente que hay que tener en cuenta que hay varios factores, por ejemplo, psicológicos, como la inestabilidad emocional y un bajo nivel cultural que pueden contribuir a resultados erróneos. Resumiendo, se puede recomendar que un boxeador aficionado tenga un chequeo médico que incluya una prueba de inteligencia antes de comenzar la carrera de boxeo con el fin de evitar molestias después con los efectos negativos que no se desean.

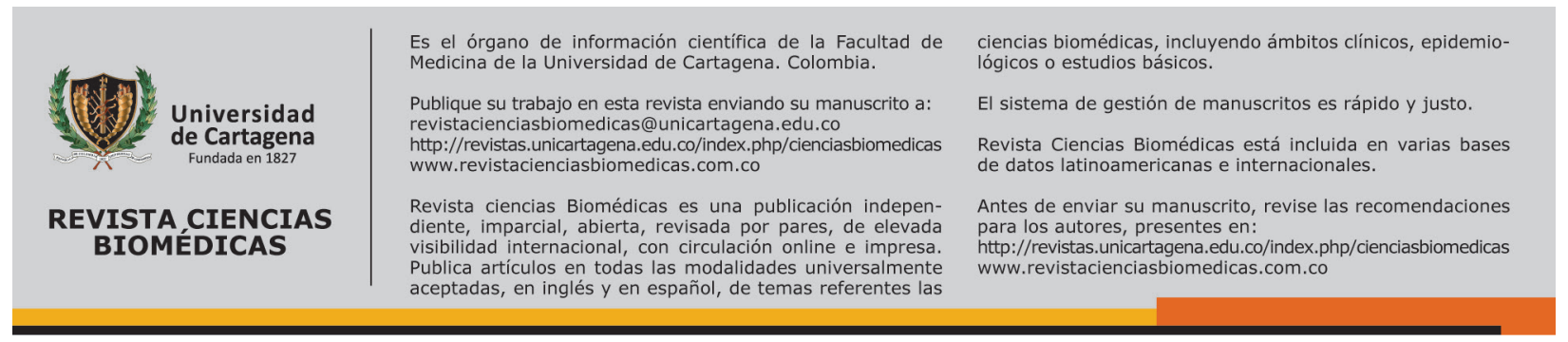

